\title{
Logistics of essential oil production
}

\author{
Rena Timirgaleeva ${ }^{1,2, *}$, Mikhail Verdysh ${ }^{2}$, Anastasia Popova $^{2}$, Natalya Polyakova ${ }^{2}$, \\ Vladimir Pashtetskiy ${ }^{2}$ \\ ${ }^{1}$ V.I. Vernadsky Crimean Federal University, Vernadsky Prospekt 4, Simferopol, 295007, Russia \\ ${ }^{2}$ FSBSI "Research Institute of Agriculture of Crimea", Kievskaya str. 150, Simferopol, 295493, \\ Russia
}

\begin{abstract}
The purpose of this article was to investigate and justify the need for the introduction of logistics management in the essential oil production industry. We have identified the main problems of using logistics by economic (business) entities. Specific characteristics that must be taken into account when implementing logistic management into essential oil production were analyzed. The main logistic tasks of economic (business) entities involved in the process of essential oil production have been described. Furthermore, we offer a one-product deterministic model of inventory management that is the basis for making economically sound logistics decisions when managing resources of essential oil production.
\end{abstract}

\section{Introduction}

Essential oil production entities face many challenges. In aggregated form, they can be divided into two main groups. The first one - problems caused by threats from the external environment, such as lack of a specific legislative and regulatory framework for essential oil production, the need to streamline the obtained essential oil raw materials in the allRussian classifiers of products and types of economic activities, the situation on foreign markets. The second one - problems caused by certain uncoordinated actions within a business entity. In the practice of the entities of essential oil production, all actions and responsibilities for their implementation in the conditions of the functioning of most enterprises are concentrated in various structural units, and the procedures for implementing these actions are not always rational. One of the approaches to the successful functioning and development of this type of production can be logistics. Its implementation will increase the efficiency of economic processes and reduce overall costs, which is, in fact, the main task of logistics management.

Analysis of several literary sources [1-5] allows us to assert that logistics at the present stage is considered as a mechanism for optimizing economic ties based on inter-functional economic compromises. Both in the Russian Federation and worldwide, the number of business entities actively using logistics as the main management concept is gradually increasing. At enterprises, departments and logistics services are created; logistics systems are formed. The main reasons that restrain the widespread use of the logistics system (as the

\footnotetext{
* Corresponding author: renatimir@gmail.com
} 
basis for the effective organization of the activity of a business entity) are certain complexity of organizing the process of its formation and the fragmentary use of logistics. At the same time, the organization of logistics in enterprises, logistics systems, and logistics supply chains is an essential factor to ensure effective management [6-8]. One of the most important properties of logistics management is the reduction of logistics costs, which constitute a significant part of all costs.

In the studies carried out by the authors of works on logistics management, we observe a fairly complete and substantiated statement of general conceptual provisions, as well as the presence of practical and theoretical reasoned ideas for the formation of directions for their use. However, the issues of the possibility of introducing modern, most adequate and acceptable methods, models and algorithms for the practical implementation of the indicated tasks are not adequately reflected in these works. Theoretical, scientific and practical, organizational, economic, economic-legal and information aspects of logistics management are considered for many industries. But for the sphere of essential oil production, it is necessary to systematize the tasks of modelling the process of logistics management of the industry, as well as to determine the most promising and acceptable methods. Thus, these aspects determined the relevance and objectives of the study.

\section{Materials and methods}

The theoretical and methodological basis included fundamental principles of logistics, legislative and regulatory acts relating to essential oil production, monographs and scientific publications of domestic and foreign scientists. In the course of the study, we used general scientific and special research methods, as well as methods of systematization and modelling.

\section{Results}

Essential oil production is the process of growing and processing essential oil raw materials along with the economic relationships that arise during these processes. The objectives of this type of production are to obtain a sufficient range of essential oil products of the required quality. The peculiarities of essential oil production require a specific approach to the implementation of logistics at various stages of its reform. There is an urgent need to review the entire system of essential oil production management to ensure its full focus on the satisfaction of the needs of the consumers.

Analyzing the state of the Russian market of essential oil products, problems that hamper the development of essential oil production were identified. One of the factors that influence the volume of grown essential oil raw materials and produced essential oil and other products is the internal and external market situation [9]. An increase in the consumption of essential oils and their derivatives is possible due to the expansion of their use in the perfumery and other industries [10-13]. An essential aspect is also the need to improve the legislative and regulatory framework of essential oil production. This will help to streamline the obtained essential oil raw materials in the all-Russian classifiers of products and types of economic activities.

Let us define the logistics of essential oil production as the process of managing the flows of raw materials, material and technical resources, finished products from an agroindustrial enterprise specializing in growing raw materials and processing them to the end consumer. Nowadays the world economy is on the verge of tremendous technological changes that, without doubt, will change not only the life and economy but also society itself [14]. The specificity of the logistics of essential oil production is the problem of cost 
optimization, which is inseparable from the problem of product spoilage, which, unlike other industries, is caused by the rapid loss of the properties of raw materials (lavender, rose, etc.), as well as the limited shelf life of oils and essential oil products. In this case, it is necessary to create special information technology for monitoring such objects, the Application of Artificial Intelligence Methods for Forming Industry Management Systems $[15,16]$. The main logistic tasks of the economic (business) entities of essential oil production are presented in the table.

Table 1. The main logistic tasks of the economic (business) entities of essential oil production.

\begin{tabular}{|c|c|}
\hline $\begin{array}{l}\text { Economic (business) entities } \\
\text { of essential oil production }\end{array}$ & Directions of the functioning of the logistics system \\
\hline \multirow{5}{*}{$\begin{array}{l}\text { Agro-industrial enterprises } \\
\text { specializing in growing raw } \\
\text { materials and processing } \\
\text { them }\end{array}$} & Cultivation of nursery plots of essential oil crops \\
\hline & Cultivation of nursery transplants of essential oil crops \\
\hline & Laying of the plantations of essential oil crops \\
\hline & $\begin{array}{l}\text { Care and protection for the plantations (topsoil loosening, } \\
\text { fertilizer and plant protection products application) }\end{array}$ \\
\hline & $\begin{array}{l}\text { Raw materials harvesting and delivery from fields to } \\
\text { processing units }\end{array}$ \\
\hline $\begin{array}{l}\text { Raw materials processing } \\
\text { units }\end{array}$ & Raw materials processing \\
\hline \multirow{3}{*}{$\begin{array}{l}\text { Essential oil products } \\
\text { producers }\end{array}$} & Inventory management \\
\hline & Warehouse management \\
\hline & Production processes management \\
\hline \multirow{5}{*}{ Mediators } & $\begin{array}{l}\text { Inventory management (by creating inventories mediators } \\
\text { synchronize the rhythms of production and consumption that } \\
\text { are especially at risk of multi-temporal fluctuations, } \\
\text { including seasonal ones) }\end{array}$ \\
\hline & $\begin{array}{l}\text { Order processing, delivery, pre-sale processing (packing, } \\
\text { packaging) }\end{array}$ \\
\hline & Warehousing and transportation \\
\hline & Physical distribution of finished goods (products) \\
\hline & $\begin{array}{l}\text { Supporting functions (quality standardization, distribution, } \\
\text { financing, information support, risk insurance, retail } \\
\text { marketing support) }\end{array}$ \\
\hline
\end{tabular}

A crucial logistical function of the economic (business) entities of essential oil production is economically sound decision-making to optimize systems and processes. This is quite problematic for this industry because of a number of specific features:

- $\quad$ rapid loss of properties of essential oil raw materials, which requires its delivery to processing units as soon as possible in line with the required conditions;

- the need to look after non-fructiferous plantings (the plantations of essential oil rose and lavender do not bear fruit the next year after planting, but technological operations still must be carried out both manually and mechanically);

- care and protection for the plantations in subsequent years (topsoil loosening, fertilizer and plant protection products application);

- $\quad$ seasonality of the collection of lavender and rose petals, which increases the risk of adverse situations;

- dependence of the volumes of lavender and rose raw materials and the quality of the obtained essential oils on weather conditions;

- $\quad$ rapid loss of properties of the harvested raw materials, which requires its rapid delivery to processing units;

- $\quad$ limited warranty shelf life for oils and other essential oil products (up to one year), the need to satisfy certain conditions to preserve the quality; 
- $\quad$ essential oil products are not end-products and are used as raw materials for other industries

- food, perfumery, cosmetic, pharmaceutical, chemical, etc. Thus, it is problematic to sell the products because of high-level competition in the market;

- sanctions, which were imposed against the Republic of Crimea. This hinders the sale of essential oil products in foreign markets, as well as the attraction of foreign investments and technologies;

- presence and influence on the logistics processes of a significant number of economic (business) entities involved in the process of essential oil production (agroindustrial enterprises specializing in growing raw materials and processing them, essential oil products producers, mediators, suppliers, consumers, government regulatory bodies, transport organizations) with their specific interests, requirements, requests, which are often vague and unclear;

- presence of probabilistic elements and accidents (weather conditions, quality of equipment/vehicles/communications, temporal and spatial unevenness of demand, etc.);

- insufficiency and incompleteness, and sometimes even lack of information, or its complete change;

- relative limitation in making proactive decisions, the influence of various sociopsychological factors on the decision-making process.

The implementation of the logistics concept will ensure the integration of economic (business) entities involved in the process of essential oil production. This will allow them to work together to get the best possible results while minimizing all kinds of costs.

\section{Discussion}

Consider this statement on one of the most important functional areas of logistics inventory management. The problem of inventory management is related to the problem of minimizing the cost function, which represents the total costs of supply, storage of the product (possible losses from spoilage, loss of profit from capital losses, etc.), as well as the costs of deficit penalties. The choice of an inventory management strategy is determined by a number of factors: demand for a product, which can be deterministic in time or random (the volume of demand or moments of demand are random); order volume; time and cost of deliveries; costs of storing stock in a warehouse; fines for deficit, which leads to losses due to irregular production, equipment downtime, etc.

To solve the problem of inventory management within the framework of the logistics system of essential oil production, we offer a one-product deterministic model, since the processed raw materials are homogeneous in their characteristics. To describe the model, we introduce the following notation:

$\mathrm{a}(t)$ - the intensity of stock replenishment, i.e. the stock level $\mathrm{A}(\mathrm{t})$ is replenished according to the ratio:

$$
A(t)=\int_{0}^{t} a(\tau) \mathrm{d} \tau
$$

$b(t)$ - the intensity of demand (consumption) of the product, its consumption during time $t$ will be equal to:

$$
B(\tau)=\int_{0}^{t} b(\tau) \mathrm{d} \tau
$$


Further, it is assumed that the quantities $a(t)$ and $b(t)$ are constant: $a(t)=a, b(t)=b$, therefore, the functions of time $\mathrm{A}(t)$ and $\mathrm{B}(t)$ are linear:

$$
A(t)=a t, B(t)=b t
$$

$n$ - is the size (volume) of delivery of the batch; $s$ - is the deficit value; $c_{1}$ - the cost of delivery of the batch, free from the batch size; $c_{2}$ - costs of storing a unit of product per unit of time; $c_{3}$ - penalty for the deficit of a unit of production per unit of time; $V(n, s)-$ total costs per unit of time.

If during the replenishment of stocks there was no demand $b=0$, the values of the maximum stock and deficit would be equal $n-s$ and $s$. With constant demand, the rate of replenishment is equal to $a-b(a>b)$ and in proportion to the value $\frac{a-b}{a}=1-\frac{b}{a}=$ $\gamma$ the maximum stock decreases

$$
\begin{aligned}
& (n-s) \gamma=n \gamma-s \gamma=\bar{n}-\bar{s} \\
& s \gamma=\bar{s} .
\end{aligned}
$$

Let us determine the values of the time intervals $t_{1}, t_{2}, t_{3}$. We have, taking into account the relations (3):

$$
\begin{gathered}
t_{1}=\frac{\bar{n}-\bar{s}}{a-b}, t_{2}=\frac{\bar{n}-\bar{s}}{b}, t_{3}=\frac{\bar{s}}{b}+\frac{\bar{s}}{a-b} \text { so } \\
t_{1}+t_{2}=(\bar{n}-\bar{s})\left(\frac{1}{a-b}+\frac{1}{b}\right)=\frac{(\bar{n}-\bar{s}) a}{(a-b) b}=\frac{\bar{n}-\bar{s}}{\gamma b}=\frac{n-s}{b} \\
t_{3}=\bar{s}\left(\frac{1}{a-b}+\frac{1}{b}\right)=\frac{\bar{s}}{\gamma b}=\frac{s}{b}
\end{gathered}
$$

The period $\mathrm{T}$ is equal to:

$$
T=t_{1}+t_{2}+t_{3}=\frac{n-s}{b}+\frac{s}{b}=\frac{n}{b}
$$

Then we find the specific (per unit of time) costs of each type. Delivery costs $V_{1}(n, s)$ taking into account equality (7) are equal to:

$$
V_{1}(n)=\frac{c_{1}}{T}=\frac{c_{1} b}{n}
$$

Unit storage costs $V_{2}(n, s)$ for the period $\left(\mathrm{t}_{1}+\mathrm{t}_{2}\right)$ :

$$
V_{2}(n, s)=c_{2} \cdot \frac{\bar{n}-\bar{s}}{2} \cdot \frac{t_{1}+t_{2}}{T}=\frac{c_{2} \gamma(n-s)^{2}}{2 n}
$$

where the average stock level is $\frac{\bar{n}-\bar{s}}{2}$. 
The specific deficit penalty $V_{3}(n, s)$ is:

$$
V_{3}(n, s)=c_{3} \cdot \frac{\bar{s}}{2} \cdot \frac{t_{3}}{T}=\frac{c_{3} \gamma_{s}^{2}}{2 n}
$$

The total unit costs $V(n, s)$, with considering (8) - (10), are equal to:

$$
V(n, s)=V_{1}(n)+V_{2}(n, s)+V_{3}(n, s)=\frac{c_{1} b}{n}+\frac{\gamma}{2 n}\left[c_{2}(n-s)^{2}+c_{3} s^{2}\right]
$$

Equating to zero the partial derivatives from the equations:

$$
\begin{array}{r}
\frac{\partial V(n, s)}{\partial s}=-\frac{c_{2} \gamma}{n}(n-s)+\frac{c_{3} \gamma s}{n}=0 \\
\frac{\partial V(n, s)}{\partial n}=-\frac{c_{1} b}{n^{2}}+\frac{c_{2} \gamma}{2}\left(1-\frac{s^{2}}{n^{2}}\right)-\frac{c_{3} \gamma s^{2}}{2 n^{2}}=0
\end{array}
$$

Find the optimal values of $n_{0}$ и $s_{0}$ :

$$
\begin{gathered}
n_{0}=\sqrt{\frac{2 c_{1} b \cdot\left(c_{2}+c_{3}\right)}{c_{2} \gamma \cdot c_{3}}}=\sqrt{\frac{2 c_{1} b}{c_{2} \gamma \rho}} \\
s_{0}=\sqrt{\frac{2 c_{1} b \cdot c_{2}}{\gamma c_{3}\left(c_{2}+c_{3}\right)}}=\sqrt{\frac{2 c_{1} c_{2} b \rho}{\gamma c_{3}^{2}}} \overline{s_{0}}=\gamma s_{0}
\end{gathered}
$$

where $\rho=\frac{c_{3}}{c_{2}+c_{3}}$ is the density of losses due to deficit.

Checking sufficient conditions (calculating the determinants of the Hessian matrix) shows that the function $V(n, s)$ has a minimum. Considering formula (7), the optimal delivery period $T_{0}$ is equal to:

$$
T_{0}=\frac{n_{0}}{b}=\sqrt{\frac{2 c_{1}}{c_{2} \gamma \rho b}}
$$

From the main relations (14) - (16), we can conclude about the influence of the intensity of stock replenishment, deficit on the parameters of the model. From formulas (14), (15) follows:

$$
\frac{\bar{s}_{0}}{\bar{n}_{0}}=\frac{s_{0}}{n_{0}}=\frac{c_{2} \rho}{c_{3}}=1-\rho, \bar{s}_{0}=\bar{n}_{0}(1-\rho)
$$

Since the ratio $\frac{t_{3}}{T}=\frac{s}{n}$, then it means that during the $(1-\rho) \cdot 100 \%$ time of the full period $\mathrm{T}$ there is no stock of the product.

Substituting the values of $n_{0}, s_{0}$ в into equality (11), we obtain the minimum value of the unit total costs: 


$$
V_{0}\left(n_{0}, s_{0}\right)=\frac{2 c_{1} b}{n_{0}}
$$

so, the delivery costs of the batch $V_{1}=\frac{c_{1} b}{n_{0}}$ are equal to the storage costs and the $V_{2}+V_{3}$ deficit penalty. The maximum value of the stock level, with considering relations (14), (17) are equal to:

$$
\bar{n}_{0}-\bar{s}_{0}=n_{0} \rho \gamma=\sqrt{\frac{2 c_{1} b \rho \gamma}{c_{2}}}
$$

From the general model, at certain values of a, c3, there follow particular models used in the management of stocks of raw materials, resources and finished products.

\section{Conclusion}

The study of the theory and practice of logistics and its systems has shown that in a situation of uncertainty in the market and insufficiently developed systems of effective management of logistical activities, logistics management is often carried out spontaneously and ineffectively. Having in mind the specificity of the logistics of essential oil production (rapid loss of the properties of raw materials, limited shelf life of oils and essential oil products), economically justified optimization solutions based on modelling the management processes of various objects and functional areas of the logistics system are necessary. The proposed model of inventory management is the basis for inventory management of raw materials, resources, and finished (end) products.

\section{Acknowledgments}

The reported study was funded by RFBR, project number 20-016-00220.

\section{References}

1. S. Modgil, R.Kr. Singh, V. Sonwaney, International Journal of Logistics Systems and Management (IJLSM) 37(1) (2020) DOI: 10.1504/IJLSM, 2020.109648

2. Ch. Martin, Logistics and Supply Chain Management. 4th Edition (Pearson Education, 2011)

3. J. Morana, Logistics (Wiley-ISTE, 2018)

4. T. Blecker, W. Kersten, C. Ringle et al., Innovative Methods in Logistics and Supply Chain Management: Current Issues and Emerging Practices (Berlin, 2014)

5. Wang Xiaoyu, Zhou Fei, 12th International Conference on Service Systems and Service Management (ICSSSM) 15330532 (2015) DOI: 10.1109/ICSSSM.2015.7170175.

6. M. Cao, Q. Zhang, J. Oper. Manag. 29, 163-180 DOI: $10.1016 /$ j.jom.2010.12.008.

7. A.Ja. Antoni, Logistics - the Eurasian Bridge, 285-290 (2016)

8. A. Rushton, Ph. Croucher, P. Baker, The Handbook of Logistics and Distribution Management: Understanding the Supply Chain 5th ed. (Kogan Page, 2014) 
9. N. Mahomed, Essential Oils: Export Market opportunity (2014)

10. M. Peters, Essential oils: historical significance, chemical composition and medicinal uses and benefits (Nova Science Pub Inc., 2016)

11. H.A. El-Shamy, Potential of Essential oils (IntechOpen, London, 2018)

12. K. Hüsnü Can Baser et al., Essential oils: Handbook of Science, Technology and Applications (CRC Press, Taylor \& Francis Group, 2016)

13. Mozaniel Santana de Oliveira, New Perspectives and Applications (2020) DOI: 10.5772/intechopen. 87266

14. R.R. Timirgaleeva, I.Yu. Grishin, CEUR Workshop Proceedings 2522, 224-235 (2019)

15. Remote sensing: The method of GIS application for monitoring the state of soils

16. I. Grishin, R.Timirgaleeva, E3S Web of Conferences 175, 06009 (2020)

17. I. Grishin, R. Timirgaleeva, CEUR Workshop Proceedings. 1. Ser. "Selected Papers of the 1st International Scientific Conference Convergent Cognitive Information Technologies, Convergent, 115-120. (2016) 